\title{
Scalar Implicature in Modern Pragmatics and Traditional Arabic Pragmatics
}

\author{
HISHAM IBRAHIM ABDULLA \\ Assistant Professor \\ Iraqi University, Iraq
}

\begin{abstract}
:
The preset paper is an attempt to see whether traditional Arab Linguists knew implicatures in general and specifically generalized quantity implicatures of the type known as "scalar" in modern pragmatic literature. These notions are associated with scholars such as Grice, Horn, Levinson and Hirschberg in modern pragmatics. In part I of this paper, the researcher gives a brief survey of the main aspects of the phenomenon: definition, types, examples, debates and different accounts of the notion as they appeared in modern pragmatic literature.

Part II of the study is an investigation into the question about whether these phenomena have a longer history than is recognized in the literature, and whether medieval Arab linguists had known them centuries before their western counterparts. Instead of putting words into the mouths of traditional Arab linguist the researcher adopted the method of quoting* them and letting them speak for themselves. Of course, some commentaries and explanations were necessary to contextualize the quotations and help the reader to understand them. Comparisons between the traditional Arabic and modern western concepts showed striking similarities between the two. The Arabic traditional concept of "Mafhoom" is the forerunner of the modern pragmatic concept of generalized quantity implicature.
\end{abstract}

\footnotetext{
* The quotations are translated into English by the researcher. The original Arabic texts are shown in the appendix at the end of the paper
} 
Key words: Pragmatics; Scalar implicature; Generalised quantity implicature; Medieval Arabic pragmatics; Principles of Islamic jurisprudence.

\section{PART I}

Scalar implicature is one type of generalized conversational implicature (GCI). As Paul Grice (1975: 314) points out, unlike particularized conversational implicature (PCI) which "is carried by saying that $\mathbf{P}$ on a particular occasion in virtue of special features of the context", (GCI) is normally carried by "the use of certain form of words in an utterance" in the absence of special circumstances.

Scalar Implicatures are quantity implicatures and their derivation is due to Grice's (1975) first maxim of quantity, which says "make your contribution as information as is required for the current purpose of the exchange".

They also depend on the existence of semantic entailment scales. These scales consist of a number of contrasted expressions, usually of the same grammatical form, which are ordered linearly by degree of informativeness or semantic strength. These contrastive sets of scalar expressions or scalar predicates, as Levinson (1983) calls them, are usually put inside angled brackets. The most famous of these scales are Horn scales, named after The American linguist, Laurence Horn who was the first to point them out. Here are some examples from (Horn, 1972)

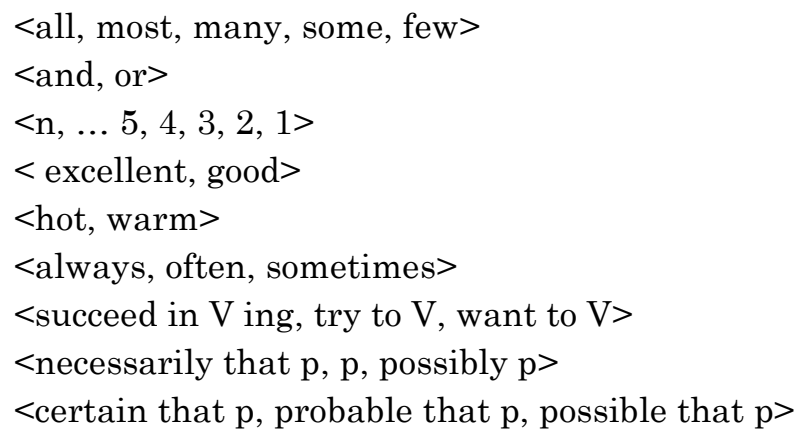


$<$ Must, should, may $>$

$<$ cold, cool $>$

$<$ love, like $>$

$<$ none, not all $>$

Entailment is a semantic relation defined in terms of truth, i.e. a proposition (p) entails a proposition (q) if and only if the truth of (p) guarantees the truth of (q)

Now given the scales and the definition, it is easy to observe that the expressions or predicates on the left side of the scale entail those on the right side, but not vice versa. Thus, the item (all) entails the item (most), and (most) entails (many) etc., but (most) does not entail (all).

We can easily notice that sentences like (1) entail sentences like (2) and not vice versa:

1 All guests are vegetarians.

2 Some of the guests are vegetarians.

3 Not all the guests are vegetarians.

But on the other hand, if we assert (2), we conversationally implicate (3), which is the negation of (1), i.e. not all the guests are vegetarians. Obviously, this is due to Grice's first submaxim of quantity, and to the first of the above Horn scales. This type of regular inference is in fact an implicature. It meets all the requirements of an implicature, especially defeasibility. Unlike entailments, implicatures are defeasible. Thus, we can cancel the implicature in (3) above, by the addition of the phrase (in fact all) as in (4), or we can suspend it by an if clause, as in 5, without any sense of contradiction:

4. Some of the guests, in fact all, are vegetarians.

5 . Some of the guests, if not all, are vegetarians.

Obviously (some) is compatible with (all), and the notion (not all) is not part of its semantic content, but only a scalar 
Hisham Ibrahim Abdulla- Scalar Implicature in Modern Pragmatics and Traditional Arabic Pragmatics

implicature regularly associated with it. Carston (1988) provides us with more examples:

6. (a) X: I like Mary. She's intelligent and good- hearted. Y: She's intelligent .

(b) Y doesn't think Mary is good- hearted.

7. (a) She won't necessarily get the job.

(b) She will possibly get the job.

In (6), the stronger expression is (intelligent and good-hearted) which entails (intelligent). By choosing the weaker expression (intelligent), B implicates that Mary is not good-hearted but only intelligent. In (7), there is a scale inversion because of the negation, therefore the weak/strong expressions are (not necessarily/ not possibly); the result is the negation of (not possibly) which is already negated. By eliminating the double negation we get (possibly). Example (6) echoes the following example from Leech (1983: 80):

8. A: We'll all miss Bill and Agatha, won't we?

B: Well, we'll all miss Bill.

Levinson (1983:135) provides us with Gricean arguments deriving inferences such as (3) from utterances like (2):

9. (i) $\mathrm{S}$ has said $\mathrm{p}$

(ii) There is an expression $q$, more informative than $p$ (and thus q entails p), which might be desirable as a contribution to the current purposes of the exchange (and here is perhaps an implicit reference to the maxim of Relevance)

(iii) $q$ is of roughly equal brevity to $\mathrm{p}$; so $\mathrm{S}$ did not say $\mathrm{p}$ rather than q simply in order to be brief (i.e. to conform to the maxim of Manner)

(iv) Since if $\mathrm{S}$ knew that $\mathrm{q}$ holds but nevertheless uttered $\mathrm{p}$ he would be in breach of the injunction to make his contribution as informative as is required, $\mathrm{S}$ must mean me, the addressee, to infer that $\mathrm{S}$ knows that $\mathrm{q}$ is not the 
case $(\mathrm{K} \sim \mathrm{q})$, or at least that he does not know that $\mathrm{q}$ is the case $(\sim \mathrm{K} q)$

Since scalar implicatures are generalized, i.e. regularly and normally understood, they were mistaken by many to be aspects of the sense of the linguistic expressions that trigger them.

The interesting thing about the above inferential arguments is that the implicatures are metalinguistic, i.e. they are derived by reference to what might have been said but was not. That is why we can cancel the implicature by using metalinguistic negation with prominent stress as in "Not SOME of them are vegetarians, ALL of them are".

Another very important feature to observe in scalar implicatures is that they are epistemically oriented. From the utterance of a weaker expression (symbolically, A (e2)), one can infer that the speaker (S) knows that a stronger expression A (e1) does not hold, or symbolically, $\mathrm{K} \sim \mathrm{A}$ (e1), rather than simply (A e1), i.e. (S) does not know that A (e1) holds. Hence the implicature is about the speaker's commitment to his knowing that $\sim \mathrm{A}(\mathrm{e} 1)$. Levinson (1983) points out that there is an equivocation in the Gricean argument between the inference $\sim \mathrm{K}(\mathrm{A}(\mathrm{e} 1))$ and $\mathrm{K} \sim(\mathrm{A}(\mathrm{e} 1))$, i.e. between the proposition that the speaker does not know that $\mathrm{A}(\mathrm{e} 1)$, and the proposition that the speaker knows that not $\mathrm{A}(\mathrm{e} 1)$. According to Levinson, empirically the inference from scalar implicature is of the stronger kind i.e. "S Knows that not p".

We will see that Arab linguists of the past were well aware of this equivocation which was a subject of debate among them, centuries ago.

\section{TWO TYPES OF QUANTITY IMPLICATURES, NOT ONE:}

Horn (1948, 1989) and Levinson (1987, 2000) discovered an anomaly in the Gricean programme, a clash of contrary forces pulling in opposite directions, especially in the generalized 
quantity implicatures (GQIs) that are created by the first and second quantity maxims: the first pulls in the direction of maximizing informativeness while the second pulls in the direction of minimization. It says "Do not make your contribution more informative than is required".

Horn proposes replacing Grice's two quantity maxim and his two manner maxims by two general principles:

(10) The Q-principle: make your contribution sufficient; say as much as you can (given both Quality and $\mathrm{R}$ )

-The R-principle: Make your contribution necessary; say no more than you must (given Q)

The Q-principle is in favor of the hearer's (H's) interest: to provide $\mathrm{H}$ with as much information as possible. It subsumes Grice's first Quantity maxim and his two manner maxims ("Avoid obscurity of expression" and "Avoid ambiguity"). The Rprinciple is in the interest of the speaker(s): to lessen S's effort as much as possible. It covers Grice's second quantity maxim, his Relation maxim and the rest of the Manner maxims ("Be brief" and "Be orderly")

Levinson's proposal is similar to Horn's with some differences concerning the manner maxim. He proposed three principles: the two main ones are the Q-principle, which is the same as Horn's, and the I-principle, which is similar to Horn's R-principle but does not encompass the manner maxims or the relevance maxim. He proposes a third principle for manner, namely the M-principle. Accompanying these three principles are three heuristics that help in getting around the bottleneck created by the slow articulation rate of human speech. They help in multiplying the informational content of any message.

Here are the two main principles and their heuristics: 
(11) Q-principle

(a) Speaker's maxim: don't provide a statement that is informationally weaker than your knowledge of the world allows.

(b) Recipient's corollary: take it that the speaker made the strongest statement consistent with what he knows.

\section{I-principle}

(a) Speaker's maxim: the maxim of minimization 'say as little as necessary' i.e. produce the minimal linguistic clues sufficient to achieve your communicational ends.

(b) Recipient's corollary: Enrichment rule 'amplify the informational content of the speaker's utterances, by finding a more specific interpretation, up to what you judge to be the speaker's m-intended point'.

(12) (a) Q-heuristic: what isn't said isn't the case.

(b) I-heuristic: what isn't said is the obvious.

In this study we will narrow the focus on the first principles/ heuristics. The first is responsible for scalar implicatures or Qimplicatures, which is the main area of our interest. The second pulls in the opposite direction creating what Levinson calls Iimplicatures. We will show that the essential ideas behind these concepts were familiar to traditional Arab linguists centuries ago.

To sum up, both Horn and Levinson subscribe to the idea that there are two informativeness principles pulling in opposite directions The Q-principle enjoins maximal informativeness, the I- or R-principle enjoins minimal; and each of them gives rise to a type of implicature which opposes the other. The first involves strengthening of what is said. Both Horn and Levinson also point out that scalar implicatures are a unified class of generalized quantity implicatures. 
Hisham Ibrahim Abdulla- Scalar Implicature in Modern Pragmatics and Traditional Arabic Pragmatics

We have already given some examples of Q-implicatures. Here are more examples from Levinson $(1987,2000)$ :

14 A "some of the boys were angels" +>not all were

B "Bill has written three books" +> not more than three

C "Her dress was red" +> not red and blue

Below are some examples of I-implicatures taken from Levinson(1987):

15(a) John turned the key and the engine started.

$+>$ He turned the key and then the engine started (temporarity)

$+>$ He turned the key and thereby caused the engine to start (causality)

$+>$ He turned the key in order to make the engine start (teleology)

( b ) If you mow the lawn, I'll give you $5 \$$.

$+>$ if and only if you mow the lawn, I will give you $5 \$$.

I-implicature is a heterogeneous class including various linguistic phenomena ranging over conditional perfection, conjunction reduction, membership categorization, definite reference, bridging inferences, indirect speech acts and even presupposition. Addressing these phenomena goes beyond the scope of the present paper. Atlas and Levinson (1981) provide us with sixteen examples. They point out that (15.a) is an instance of conjunction buttressing, and (15.b) is an example of conditional perfection. Obviously these I-implicatures go for a stronger or more informative interpretation in line with stereotypical expectations. Unlike Q-implicatures, they are not based on the negation of a stronger possible statement. Iimplicatures are enrichments of what is said: they are positive in character, whereas Q-Implicatures only exclude something else that might have been said but was not. They are negative in nature.

However, Levinson (1987: 122) points out that Tanya Reinhart suggests that "there must be some unitary principle 
Hisham Ibrahim Abdulla- Scalar Implicature in Modern Pragmatics and Traditional Arabic Pragmatics

that will subsume the Q- and I- principles, especially as both induce inferences more informative that what was said".

\section{ARE SCALAR IMPLICATURES A UNIFIED CLASS?}

We have seen that scalar implicatures owe their existence to semantic entailment scales, the most famous of which are Horn scales. These semantic entailment scales involve sets of linguistic alternates ordered linearly, the strong one entailing the weaker ones and not vice versa. The alternates should be equally lexicalized and about the same semantic relation.

However, many linguists recognized that scalar implicatures may be derived from pragmatically defined scales and assumptions beyond the lexicon. Fauconnier (1975, in Levinson 2000) recognized the pragmatic nature of those ad hoc scales or nonce scales, as Levinson calls them.

Julia Hirschberg (1985) also discovered that Horn's linearly ordered scales of entailment relation are not the only kind of orderings that give rise to scalar implicatures. They are only one small type among many others. Various other linear and hierarchical relations which create partially ordered sets (posets) also work in the same way.

Hirschberg proposes a theory of scalar implicature which encompasses both types of scalar implicatures: those based on the lexicon and those based on pragmatically salient posets. One consequence of her theory is that she denies the distinction between (GCI) and (PCI).

Levinson (200) dubs the pragmatically given scales "Hirschberg scales", Here are some examples taken from Hirschberg:

\section{Ordered entities:}

16. ranked entities:

A: Is Jill a professor yet?

B: She's senior lecturer. 
Hisham Ibrahim Abdulla- Scalar Implicature in Modern Pragmatics and Traditional Arabic Pragmatics

Implicature: Jill isn't a professor

17. whole/part relation:

A: Did you manage to read that chapter I gave you?

B: I read the first couple of pages.

Implicature: B did not read the chapter

18. instance-of:

A: do you have any juice?

B: I have grape, orange and tomato

Implicature: B does not have any lemon/apple/etc.

\section{Unordered entities:}

19 A: did you get Paul Newman's autograph?

B: I got John Woodward's.

Implicature: B didn't get Paul Newman's autograph

20 A: Do you have apple juice?

B I have grape or tomato or orange.

Implicature: B doesn't have any apple juice.

According to Levinson (2000: 105), 'she also independently notes that lexical sets of incompatibles can give interesting implicatures - affirmation of one implicates denial of another, whereas denial of one alternate implicates affirmation of another'

(21) A: "Do you speak Spanish?"

B: " I speak Portuguese"

+> 'I don't speak Spanish'

Levinson (2000: 106) also gives the following unordered items: (22) 


\section{Unordered items}

(a) affirming an alternate L1 implicated other alternates L2 or Ln are false or unknown ("L1" +> not- L2)

(i) "I've read chapter 1"

$+>$ 'not chapter 2 '

(ii) " you need a typhus shot"

$+>$ 'not cholera too'

(b) Denying an alternate L1 implicates that other alternates L2 or Ln may be true or unknown ("not L1" $+>$ L2)

(i) "it's not an oak"

+> 'it maybe a maple or ...'

(ii) "She doesn't have a boy"

$+>$ 'she has a girl'

Obviously the implicature in the last examples is due to a lexical set of incompatibles: the affirmation of one implicates denial of the others. We can see that the classical Horn scales are just a special case where $(\mathrm{O})$ (the ordering relation) is entailment.

However, Levinson (200) points out that a serious problem of the theory is that it will overgenerate implicatures because it offers no constraints on scalehood. Even the entailment relation will overgenerate if not restricted by the constraints on Horn scales: we do not implicate the negation of everything that entails what we said. We will see that Ghazzali (D. 505/ 1111) ${ }^{*}$ made similar remarks and this problem was a source of heated debates among traditional Arab linguists.

Relevance theorists' account of implicature is different from Grice's and his followers'. Sperber and Wilson $(1986,1995)$

\footnotetext{
${ }^{*}$ I follow a convention used by orientalists when I mention the year of the death of scholars $\mathrm{AH}$ first, then $\mathrm{AD}$. As for referencing modern books, I use the usual modern method of putting the year of publication after the name of the author, but for traditional Arabic references I mention the name of the book.
} 
Hisham Ibrahim Abdulla- Scalar Implicature in Modern Pragmatics and Traditional Arabic Pragmatics

advocate a reanalysis of many GCIs as pragmatically determined aspects of explicit content. Kempson (1986) and Carston (1988) reanalyzed scalar or quantity implicature in that direction.

\section{Part II}

\section{SCALAR IMPLICATURE IN ARABIC LINGUISTIC TRADITION}

In this section we will make a comparison between the modern pragmatic concepts we have surveyed so far and very similar concepts in Medieval Arabic linguistic tradition. These are mostly taken from the work of "Usulies" (Islamic jurisprudents) who were the theorists or philosophers of Islamic law, working within the field of "usul al fiqh" (principles of jurisprudence). Their aim was to reach the precisely intended meaning of the holy texts, i.e. the holy Quran and prophetic tradition (Hadeeth).

According to the majority of Usulies, linguistic meaning falls into two types: "mantooq" (the uttered or said) and "mafhoom" (the understood or implicated). Mantooq is subdivided into explicit (mantooq sareeh) and inexplicit (mantooq ghair sareeh). The nearest term to mantooq in modern pragmatics is Grice's "what is said", and mafhoom constitutes part of generalized implicature, specifically generalized Quantity implicature, which includes Q- and Iimplicatures.

In the first part of this study, we have seen that some pragmatists claimed the existence of an anomaly in Grice's prorgramme, namely the clash between Q- and I-implicatures, one minimizing informativeness and the other maximizing it. However some linguists like Tanya Reinhart argued that both types of implicature are actually enrichments and induce inferences more informative than what was said. Thus, the only 
difference that remains between the two types of implicature is that the Q- or scalar implicatures are negative in character, whereas the I- ones are positive.

Usulies did not miss this fact, therefore they ignored the informativeness criterion and adopted a negative/positive criterion and they divided mafhoom into "mukhalafa" (negative or opposite implicature) and "muwafaqa" (positive or congruent implicature). Henceforth we will use the abbreviated form "Mafhoom(-)" to refer to the first, and "Mafhoom(+)" to the second.

Mafhoom(+) is one case of I-implicature. It is a positive inference and is an enrichment of what is said. The problem with Usulies' works is that they lack variety in the examples. They keep repeating one or two examples and go into details with the classifications, definitions, and analyses. The mostquoted example is, as usual, a verse from the holy Quran, enjoining children not to show any disrespect to their parents ((say not to them "uffin" a word of disrespect)).

What is said is a prohibition of saying the word "uffin" which is the least sign of impatience or disrespect; the implicated Mafhoom(+) is a fortiori not to harm them in a more disrespectful way such as beating them or swearing at them or killing them. Let us quote Taftazani (D. 793/1390) in his gloss on Igie (vol.2, p.172):

Mafhoom is divided into muwafaqa and mukhalafa, because the status of the unsaid is either congruent with what is said, whether negative or positive, or not. The first is muwafaqa... He gave examples, such as ((say not to them a word of disrespect "uffin")). Thus we know from the status of saying "uffin", which is what is said, the status of beating, which is not said, both being congruent in prohibition. Another example is ((so whosoever does an atom's weight of good, shall see it (8) and whosoever does an atom's weight of evil, shall

\footnotetext{
* Surat 17, verse 23.

EUROPEAN ACADEMIC RESEARCH - Vol. III, Issue 7 / October 2015
} 
see it.) ${ }^{* *}$ What is said is an atom's weight; what is unsaid is what is more than that, and the judgment is one: both will be rewarded. (text $\mathbf{A})$

Levinson should have put these cases of "muwafawa" on top of his list of I-implicatures. As for Horn (1978: 149), he gives examples very similar to the Mafhoom(+) examples, but he considers them as cases of "negative strengthening":

I don't care a hoot, damn, farthing, fig, hang,

I don't give a plugged nickel, red cent

It's not worth a

That Mafhoom(+) is a case of GCI and not part of what is said can be proved by the defeasibility test. Like all types of implicature, they are defeasible or cancellable as Ghazzali (Mustasfa vol.2, p.190) points out that unless we know what is said and what is intended by it, the inference will not take place:

Were it not for our knowledge that the verse was intended to show great honour and respect to parents, we wouldn't have inferred the prohibition of beating and killing from the prohibition of saying "uffin"; for the Sultan who decreed the killing of the king, might say 'don't say "uffin" to him but kill him'. (text B)

Obviously what Ghazzali is referring to above is what modern pragmatists call "metalinguistic negation" with prominent stress, as in the example we previously gave in part I: "Not SOME of the guests are vegetarians, ALL of them are." This type of negation changes the Q-implicature into I-implicature or vice versa, as in Ghazzali's example, where the Mafhoom(+) is changed into Mafhoom(-)

We should make it clear right at the outset that the relationship between these pairs of Arabic and western

\footnotetext{
** Surat 99, verses 7,8 .

EUROPEAN ACADEMIC RESEARCH - Vol. III, Issue 7 / October 2015
} 
Hisham Ibrahim Abdulla- Scalar Implicature in Modern Pragmatics and Traditional Arabic Pragmatics

concepts is not one of identity, but of similarity. Mafhoom(+) is one case of I-implicature, the unsaid in both cases being more informative than what is said. However the examples of Iimplicature are so varied and heterogeneous that putting them in one homogeneous class has been much debated. On the other hand, Mafhoom(-) is similar to Q- or scalar implicature only on the sense proposed by Hirschberg, i.e. not restricted to Horn's linearly ordered scales of items in an entailment relation.

\section{SCALAR IMPLICATURE AND MAFHOOM(-)}

We would be on solid ground if we compare Mafhoom(-) to the widened concept of scalar implicature in the Hirschberg sense. We have already outlined her proposal and compared it to Horn's and Levinson's. The major difference is that she widened the concept to include all sorts of ordering and partial ordering whether ranked linearly or based on alternative values. We also gave enough illustrative examples to explain the ideas of all three linguists. Now we need to look at the Arabic concept of Mafhoom(-) is some detail.

\section{Mafhoom(-): Definition, Types and Conditions:}

The literature on Mafhoom(-) is so vast in traditional Usulie books that it is impossible to give an exhaustive survey of the subject, which is certainly beyond the scope of this study. I will largely confine myself to a consideration of its definition and conditions in the Usulies literature; and even here we have to be selective. Let us begin with its definition. According to Amidi (D. 631/ 1233), in Mafhoom(-), unlike Mafhoom(+), the inference from what is unsaid is in contrast to what is said (Amidi's Ihkam, vol.3, p.99). It arises when we restrict a predication by a constraint so that when the constraint is negated the predication is also negated. The most quoted examples are the following from the prophetic tradition: 
Hisham Ibrahim Abdulla- Scalar Implicature in Modern Pragmatics and Traditional Arabic Pragmatics

(23) Payment of (zakat) legal alms is obligatory on unfoddered sheep

$+>$ It is not obligatory on foddered sheep.

(24) Procrastination of the wealthy is unfair.

$+>$ Procrastination of the poor is not unfair.

The restriction should be a relevant justification for the predication; otherwise the implicature (Mafhoom(-)) will not arise. The justification in (23) is of course that foddered sheep cost their owner the price of fodder. So the exemption from zakat is a measure to alleviate the cost. In (24) the relevance of the implicature is that, unlike the wealthy, a poor debtor may not have the money to pay back his debt so his procrastination is not so unfair.

Unulies were aware of the role played by relevance (munasaba) in the identification of Mafhoom(-). We will return to this, but now let us look at some example mostly taken from shawkani (D. 1255/ 1839) in his (Irshad, p.180) and Ghazzali's (Mustasfa vol.2 p.191). The examples come in the context of their classification of Mafhoom(-) into types (e.g. those of attribute (modifier), number, noun (proper, substantive, generic), condition, extent, etc.)

\section{(25) Types of Mafhoom(-) with examples:}

(a) Attribute (modifier)

"Payment of zakat is obligatory on unfoddered sheep".

$+>$ It is not obligatory on foddered sheep.

(b) Number:

((Flog them with eighty stripes) $)^{*}$

$+>$ no more no less than eighty stripes.

\footnotetext{
* Surat 24 Verse 4

EUROPEAN ACADEMIC RESEARCH - Vol. III, Issue 7 / October 2015
} 
Hisham Ibrahim Abdulla- Scalar Implicature in Modern Pragmatics and Traditional Arabic Pragmatics

(c) Noun (proper, substantive, generic)

"I saw Zaid."

+> I did not see other than Zaid.

"Payment of zakat is obligatory on sheep"

$+>$ it is not obligatory on other animals.

(d) Condition:

((and if they are pregnant, then spend on them...)) *

$+>$ if they are not pregnant, then you do not have to spend on them.

(e) Extent:

((and do not approach them until they are clean) $)^{* *}$

$+>$ you may approach them after they are clean.

There are many other types of Mafhoom(-) such as time, place and state. However some Usulies rightly argued that this classification is superfluous, and that all the various types boil down to the attribute type and to restrictive modification. The concept of restrictive modification is central to Mafhoom(-) and this is what Usulies mean when they reduce all other types to that of attribute (modifier). Shawkani in his (Irshad, p.180) makes out a good case for it:

What usulies mean by "attribute" is the restriction of a general word by another word specifying some of its senses... and they do not mean only adjectives. So with rhetoricians; what they mean by "attribute" is sense attribute, not adjective. It is grammarians who use "attribute" exclusively to refer to adjective. The majority [of usulies] rightly adopted the mafhoom of attribute, since it is a fact of Arabic that if something can be described using one or the other of two attributes, and only one was used to the exclusion of the other, then the intended meaning would be restricted to

\footnotetext{
* Surat 65 verse 6

** Surat 1 verse 222

EUROPEAN ACADEMIC RESEARCH - Vol. III, Issue 7 / October 2015
} 
Hisham Ibrahim Abdulla- Scalar Implicature in Modern Pragmatics and Traditional Arabic Pragmatics

that which has that attribute to the exclusion of the other. (my emphasis) (text C)

Obviously the emphasized lines show an awareness of the most important feature of scalar implicature according to Levinson (1987, 2000), namely the existence of a contrast set of alternates, the assertion of one of which implicates the negation of the other(s). This contrast, guarantees that the Mafhoom(-) or Q-implicature will arise even in the weakest type, which is noun Mafhoom. Most Usulies argued that no Mafhoom(-) or implicature will arise when we use a noun (whether proper, substantive or generic) because to say that Zaid came does not implicate that nobody else came. We need to address this issue in more detail.

\section{The Noun Mafhoom between Usulies and Hirschberg:}

It is widely believed among Usulies that of the many types of Mafhoom(-) implicatures, the noun Mafhoom(-) is the weakest and the least tenable. It might be interesting here to observe that the vast majority of alternates in Horn's scales, if not all, are not nouns but attributes or modifiers in the wide Usulie sense explained above, which is not restricted to adjectives. However, the items in Hirschberg's scales include many nouns (proper, substantive and generic). In fact most of them are of that class, and this is a telling feature of Hirschberg's theory of scalar implicature. This also explains why she did not restrict the phenomenon to Horn's linear entailment scales, but extended it to include a variety of partially ordered sets (posets) that are created by linear or hierarchical relations and otherwise. A logical consequence of this is that scales (or contrast sets) are often pragmatically created as fauconnier (1975) pointed out. Hirschberg generalized this idea of pragmatically or ad hoc given scales or contrast sets, as we have seen in the examples in (16-21) and Levinson's in 22 
above. The implicatures in (18-22) are due to unordered contrast sets. They are cases of noun Mafhoom(-).

The idea that many scales are pragmatically given led Hirschberg to deny the distinction between GCIs and PCIs and advocate the reduction of all scalar GCIs to PCIs, the former being based on the lexicon and the latter based on salient contrast in the world. However, Levinson (2000: 107) remarks that 'the theory will overgenerate implicatures because it offers no constraints on scalehood'.

It is interesting to notice the similarity between Levinson's and Ghazzalie's reservations about this issue. Ghazzali (Mustasfa, vol.2, p.193) is an opponent of the advocates of Mafhoom(-). He denies not only noun Mafhoom(-) but even the attribute (modifier) Mafhoom(-); he believes they are on a par. One reason he offers is the problem of overgeneration:

So if one says "the black man stood up or left or sat down", it does not means that the white man did not, it only means that nothing was said about the white... Thus saying "I saw Zaid" does not negate seeing his clothes or his horse or servant or anyone other than Zaid, for this would mean that to say "Zaid is knowledgeable" is blasphemy because it means that neither Allah nor his angels nor his messengers are knowledgeable; and that to say "Jesus is a prophet" is blasphemy because it means denying the prophethood of Mohammed (pbuh) and all other prophets. (text D)

What Ghazzali is saying is that if you subscribe to the theory of Mafhoom(-) implicature, then there will be no limit to the negative implicatures that arise according to its proponents. But he rejects the theory and the alleged implicatures it generates.

The solution to this problem of overgeneration comes from Sperber and Wilson's $(1986,1995)$ relevance theory. Only relevant implicatures are considered by the addressee because 
Hisham Ibrahim Abdulla- Scalar Implicature in Modern Pragmatics and Traditional Arabic Pragmatics

human cognition is relevance-oriented, and relevance is a pragmatic concept closely tied to context.

Contrast sets, which are the source of implicature, are often context- created. In the examples in (6) and (8) above, and (26) below (taken from Smith and Wilson 1979) the contrast is pragmatically created:

26. (a) Well, it won't be Patrick White.

(b) Barbra Cartland will win the Literature Prize.

Obviously (26.b) is an implicature of (26.a) in a context where the Nobel Prize committee has to choose between Cartland and White for the prize.

A strikingly similar example is often given by Usulies. Amidi in his (Ihkam, vol.3, p.118) repeats it:

If one says "Shafiite jurists are good imams", the Hanafite jurists and others among the audience will be disgusted and refuse to hear it, not because of one's describing the Shafiite in that way, but because of the implication that non-shafiite are not decribed like that. (my emphasis) (text E)

In the context of Islamic jurisprudence, Shafiites and Hanafites were famous for being rivals, like Cartland and White in the above example. All the above examples with the exception of (6) are cases of noun Mafhoom(-), where the contrast is between entities not attributes.

\section{Ghazzalie's Rejection of Attribute Mafhoom:}

It is generally believed among Usulies that the most important mafhoom(-) is that of attribute or modifier, and we have seen that most types of mafhoom(-) can be reduced to that of attribute or modification. The central argument of the advocates of mafhoom(-) is that specification or modification has to have some relevance, or "fa'ida", i.e "cognitive effect", as relevance theorists call it. To put it simply, it is the useful information the hearer is rewarded for the cognitive effort he 
Hisham Ibrahim Abdulla- Scalar Implicature in Modern Pragmatics and Traditional Arabic Pragmatics

exerts in processing the utterance. According to Sperber and Wilson (1986, 1995), human communication is relevanceoriented and the rational communicator does not cost his hearer the processing effort gratuitously.

In his attempt to refute the claim of the advocates of mafhoom(-), Ghazzali (Mustasfa vol.2, p.200) starts with a summary of their main argument:

To specify or modify something has to have some useful relevance, for if both the unfoddered and the foddered [sheep], and both the virgin and non- virgin [woman], and both the intentional and unintentional [action] were equal, then why should some be specifically mentioned, while the judgment is all - inclusive, and information is needed on both. Hence the only motive for it is to restrict the predication, otherwise what is said would be nonsense. (text F)

The interesting thing in this text is the implicit awareness of Grice's quantity maxim and Sperber and Wilson's relevance. Now let us look at Ghazzali's response to one aspect of the above argument:

The second [aspect] is that the basis of this argument has two sources: one is that there has to be some relevance for this modification (specification); the second is that there is no relevance or significance but the restriction of the predication. Then the conclusion is that it is [i.e. the restriction is the significance]. That there must be some significance is given; but the second source: that there is no significance but this [restriction] is not given. For maybe there is in it some [other] significance, since significance is not confined to this. Rather the reasons for specification are numerous, and the restriction of predication is only one of them. If you say that if it had some significance or a reason other than restriction of the predication, we would have known it, our reply would be: why do you assume that every significance should be known to you? Maybe it is there but you couldn't find it. It is as if you made the negation of knowing the significance equal to knowing the negation of significance, and this is wrong. 
Hisham Ibrahim Abdulla- Scalar Implicature in Modern Pragmatics and Traditional Arabic Pragmatics

So the basis of this evidence is the ignorance of another significance. (my emphasis) (text G)

What is at stake in these Usulie debates is the question whether specification or modification is always restrictive or not. The advocates of Mafhoom(-) believe it is, otherwise the modification is an irrelevant, and hence, irrational act which goes against Sperber \& Wilson's principle of relevance, costing the hearer to process the modifier gratuitously without any reward. Of course they exempted some cases where modification is non-restrictive, and they explained these cases as violations of the conditions they set up as guarantees for mafhoom(-) to arise.

The opponents who deny mafhoom(-) use these very cases as counterexamples against the arguments proposed in support of mafhoom(-), insisting that restrictive modification, which triggers mafhoom(-), is only one of many functions that a modifier performs.

A very interesting and sophisticated idea to observe in the above text is Ghazzali's distinction between epistemically strong and weak negation which Levinson pointed out: the equivocation between $\sim \mathrm{K}(\mathrm{A}(\mathrm{e} 1))$ and $\mathrm{K} \sim(\mathrm{A}(\mathrm{e} 1))$, i.e. between "the speaker does not know that A (e1)", and "the speaker knows that not A (e1)". The emphasized lines in the Ghazzalie text show that Ghazzali, unlike Levinson, favours the weaker negation, i.e. "S does not know that P", in the case of Mafhoom() or implicature.

Shawkani (Irshad, P. 179) gives eight conditions set up by Usulies to guarantee the existence of Mafhoom(-). These conditions are an indirect way of saying that Mafhoom(-) is not a failsafe algorithm and that it is defeasible when the conditions are not met. The most important one to which most of them can be reduced is the condition that the modification or specification should be restrictive, i.e. a modifier for a specific purpose which is essential for identification; it should not be 
non- restrictive, i.e. a modifier for additional (parenthetic) information which is normally or characteristically the case, and is not essential for identification. A restrictive modifier expresses conditional relationship whereas a non-restrictive one expresses a parenthetic relationship. Hence the strongest Mafhoom(-) according to Usulies is that of the conditional: even that of attribute can be reduced to condition, as can be seen from (27-a) which can be reduced to (27-b) with its Mafhoom(-) in (27-c): *

27. (a) Procrastination of a wealthy debtor is unfair.

(b) If the debtor is wealthy, procrastination is unfair.

(c) $+>$ If the debtor is poor, procrastination is not unfair.

As an example of non-restrictive modification which violates the above condition of Mafhoom(-), Usulies quote surat (3), verse (130):

28. (a) ((Devour not Usury doubled and multiplied)).

(b) prevented Mafhoom(-): you may devour Usury not doubled or multiplied.

Of course it is a commonplace fact of Islamic law that usury of any type is unlawful. Now, postmodifiers are usually restrictive, so the predicted Mafhoom(-) implicature is that usury is lawful if it is not multiplied or doubled. This prediction, however, is wrong because in this case the postmodifier is non- restrictive due to the fact that it adds parenthetical, not conditional, information: it was the usurer's normal and characteristic practice to ask debtors either to pay back on time or the debt will be doubled and multiplied. To quote Shawkani (Irshad, P.180):

\footnotetext{
* Of course one can see it the other way round and use the example to argue that the conditional is reduceable to attribute, as some Usulies did. But according to Usulies, the conditional mafhoom is stronger than the attribute mafhoom.
} 
An example is god's verse ((Devour not usury doubled and multiplied)), as no Mafhoom(-) will arise from doubling, because the verse was revealed to forbid what they used to take owing to the postponement of payment. When payment was due, they used to say "Either you pay or the interest will double. Thus his original debt will multiply many times. The verse was revealed on this issue. (my emphasis) (text $\mathbf{H}$ )

\section{Is Mafhoom(-) of Condition a Q- or an I-implicature?}

We have previously seen that Atlas and Levinson (1981) and Levinson (1987, 2000) classify the inference from (14.b) (repeated below for ease of reference), under the rubric of Iimplicature:

14. (b) If you mow the lawn, I'll give you $5 \$$.

$+>$ If and only if you mow the lawn, I'll give you $5 \$$.

Paradoxically in Atlas and Levinson (1981) the inference from (14.b) is characterized as (29) below:

29. If you don't mow the lawn, I won't give you five dollars.

But then this is a clear example of Q-implicature not Iimplicature, or to use the Usulie terminology, it is "Mafhoom mukhalafa", not "Mafhoom muwafaqa", as the inference is of a negative character.

The reason why Levinson did not classify the inference from (14.b), which he considers a case of conditional perfection, as a Q-implicature is because it violates his constraint requiring equal lexicalization, i.e. the meaning of "if and only if" (iff) is not lexicalized in one word as in "if". Thus, these two expressions cannot make a Horn scale so as the assertion of the weaker "if" would implicate the negation of the stronger "iff". The result is that Levinson has to consider (14.b) as a case of Iimplicature, where "if" is enriched to mean "iff". 
Hisham Ibrahim Abdulla- Scalar Implicature in Modern Pragmatics and Traditional Arabic Pragmatics

However, according to Levinson (2000), Van der Auera (1995), 1997) suggests a better explanation taken from the heritage of Ducrot: conditional perfection is actually a scalar Qimplicature: by asserting just one conditional, the speaker implicates that no other conditional is required for the consequent to be the case.

It is regrettable that Arabic Linguistic heritage is ignored in this respect. What Van der Auwera and Ducrot suggest was a well- known idea in the Usulie linguistic circles centuries ago. Taftazani (Hashia on Igie, vol.2, P.181) and Ibn Humam (D. 861/ 1456) in his (Tahrir Vol.1, P.101) both subscribe to the idea, and below is a quote from Naini (D. 1355/ 1936) (in Jamaluddin, 1980, P. 285):

If there was an alterative to the condition that applies instead of it sometimes, it would have been necessary to restrict the mentioned condition with it using the conjunction "or"; so we can say for example "If Zaid visited you or fell ill, then be generous to him ". since it [the alternative condition] was not mentioned, and the condition was mentioned by itself, the negation of the alternative is certain, and this is what is meant by restricted conditional. (text I)

\section{CONCLUSION:}

We have seen that the vast majority of Quantity implicatures whether scalar or non- scalar, ordered or unordered, are cases of Mafhoom. It encompasses all negative implicatures that arise from restrictive modification whether within scales or outside them. Of course it is nearer to Hirschberg's comprehensive theory than to Horn's, which is limited to entailment scales. All entailment scales result in negative* implicatures, but not all

\footnotetext{
* of course if the sentence in question is negative, the implicature will be positive due to double negation, and that is why Usulies do not call it " negative " implicature but "Mukhalafa", which means "opposition" whether the sentence in question is positive or negative as Taftazani explicitly stated when he defined the term in (textA)
} 
negative or opposite implicatures are the result of entailment scales. They are the result of contrast sets, which may be pragmatic not semantic:

It is beyond the scope of this study to discuss and compare every aspect of the theories of Mafhoom and scalar implicature. We have selected aspects of the theories and have shown strong similarities between the two, especially the Hirschberg version. Both theories give rise to negative implicature. The inference in both is epistemically modified and this was the subject of debate among Usulies: whether it is that the speaker does not know that (p), or that he knows that not (p).

We have also looked in some detail at the implicature that arises from conditional constructions. We have noticed that Levinson and Atlas classify it under the rubric of I-implicature, whereas it tops the list of the types of Mafhoom(-), which is the Usulie equivalent of Q-implicature. Ducrot and Van der Auwera followed the example of Usulies in that particular aspect, whether they were well - informed about Usulie linguistics is a question for future research to answer.

\section{ARABIC REFERENCES:}

Amidi, Sayfuddin (1983) Al-Ihkam. Al-Ilmiya Press, Beirut.

Ghazzali, Abu- Hamid (1904) Al-Mustasfa. Ameeria Press,Bulaq.

Ibn - Humam, Kamaluddin (undated) Al- Tahrir. Beirut: Dar al Kutub Al- Ilmia

Jamaluddin, Mustafa (1980) Al- Bahth Al- Nahwi indal Usuliyeen. Baghdad: Al- Rasheed Press.

Shawkani, muhamed Ali (1937) Irshad Al- Fuhul. Egypt: Halabi Press.

Taftazani, Sa'adudin (1899) Hashia on Igie's Gloss. Bulaq: Ameeria Press. 
Hisham Ibrahim Abdulla- Scalar Implicature in Modern Pragmatics and Traditional Arabic Pragmatics

\section{ENGLISH REFERENCES:}

Atlas, J. and Levinson S. 1981. It-clefts, informativeness, and logical form. In Cole, P. 1981. Radical pragmatics. New York: Academic Press

Carston,R. 1988. Implicature, expliature and truththeoretic semantics. In R. Kempson (ed.), Mental representations. Cambridge, Cambridge Universty Press.

Carston,R. 1997 Informativeness, relevance and scalar implicature. In R.Carston and s. Uuchida (eds.) Relevance theory: application and implications.

Grice, H.P. (1975) Logic and Conversation. In Cole and Morgan (1975).

Hirschberg, J. (1985)(1991) A theory of scalar implicature. New York: Garland.

Horn, L.R. (1972) On the Semantic Properties of the Logical Operators in English. Indiana University Linguistics Club.

Horn, L.R. 1978. Some aspects of negation. In J.H. Greenberg (ed.) Universals of Human Language, vol. 4: Syntax. Stanford: Stanford University Press.

Horn, L.R. 1989. A natural history of negation. Chicago: University of Chicago Press.

Leech, J.N. (1983) Principles of Pragmatics. Longman, England.

Levinson, S.C. (1983) Prgmatics. Cambridge: CUP.

Levinson, S.C. (1987) Minimization and Conversational

Inference. In Verschueren and Papi (eds.) (1987).

Levinson, S.C. 2000. Presumptive meanings. Cambridge, MA: MIT Press.

Schmerling, S. 1970. A note on negative polarity. Unpublished ms. Champaign-Urbana

Smith, N., and Wilson, D. (1979) Modern

Linguistics. Harmondsworth: Penguin. 
Hisham Ibrahim Abdulla- Scalar Implicature in Modern Pragmatics and Traditional Arabic Pragmatics

Sperber, D. and Wilson, D. (1986) Relevance. Blackwell, Oxford.

Sperber, D. and Wilson, D. (1995) Relevance. Blackwell, Oxford.

Van der Auwera, J. 1995. Conditional perfection. In A. Athanasiqdou and R. Dirven (eds.), On conditionals again. Amsterdam: Johan Benjamins. 


\section{Appendix}

\section{The Original Arabic Texts Quoted in Translation}

$(\operatorname{text} \mathrm{A})$

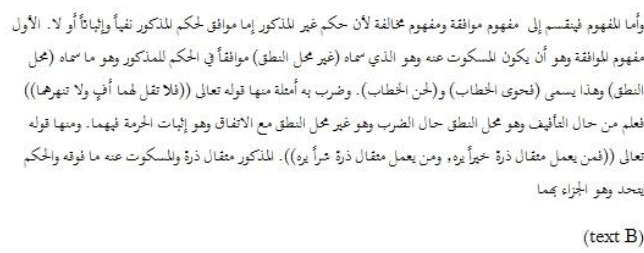

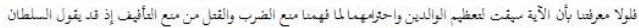

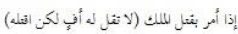

(text C)

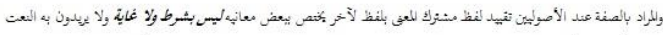

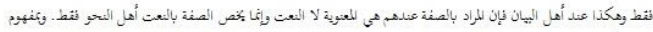

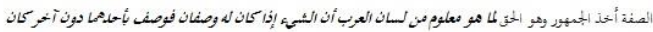

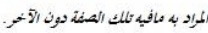

(text D)

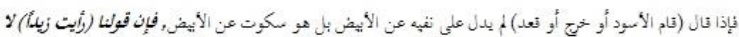

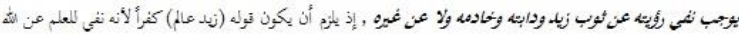

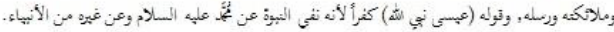

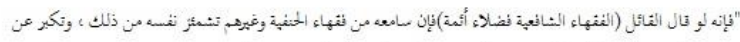

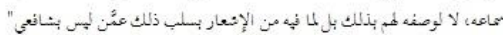

(text F)

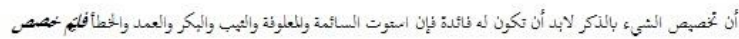

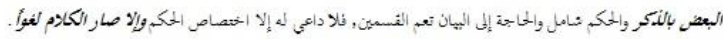

(text G)

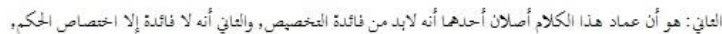

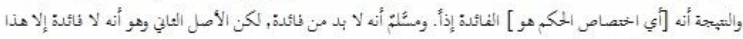

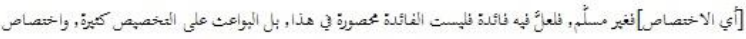

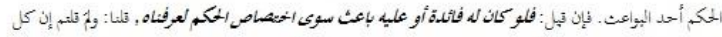

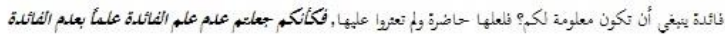

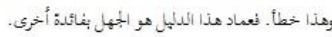

(text $\mathrm{H}$ )

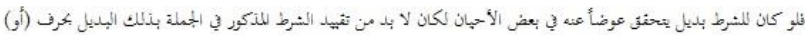

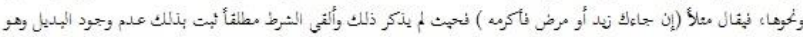

